\title{
Effect of Carbon Dioxide Removal Systems on Volatile Profiles and Quality of 'Hayward' Kiwifruit Stored in Controlled Atmosphere Rooms
}

\author{
N. Lallu ${ }^{1}$, J. Burdon, \\ D. Billing, D. Burmeister, \\ C. Yearsley, S. Osman, \\ M. Wang, A. Gunson, and \\ H. Young
}

Additional Index words. Actinidia, fruit, storage, volatiles, rots, physiological pitting, firmness

SumMary. There are three main systems for the removal of carbon dioxide $\left(\mathrm{CO}_{2}\right)$ from controlled atmosphere (CA) stores: activated carbon (AC) scrubber, hydrated lime scrubber, and nitrogen $\left(\mathrm{N}_{2}\right)$ flushing. Each system is likely to have a different effect on the accumulation of volatiles other than $\mathrm{CO}_{2}$ in the store atmosphere, and these volatiles may influence the storage performance of the produce. 'Hayward' kiwifruit (Actinidia deliciosa) were stored at $0{ }^{\circ} \mathrm{C}$ $\left(32.0{ }^{\circ} \mathrm{F}\right)$ under $2 \%$ oxygen $\left(\mathrm{O}_{2}\right)$ and $5 \% \mathrm{CO}_{2}$ in $\mathrm{CA}$ rooms fitted with one of the three systems. In a fourth CA room, fruit were stored at $0{ }^{\circ} \mathrm{C}$ under air conditions. All four stores had their atmosphere scrubbed for ethylene. The store atmospheres and fruit firmness were monitored at intervals up to 27 or 14 weeks of storage in the 1999 or 2000 season, respectively.

HortResearch, Mount Albert Research Centre, Private Bag 92169, Auckland, New Zealand.

Acknowledgments. The authors gratefully acknowledge Punchbowl Coolstores Ltd for the provision of frui in 2000 . The work was funded by the New Zealand Foundation for Research, Science and Technology, Contracts CO6820/CO6X0006.

${ }^{1}$ To whom reprint requests should be addressed phone: 64-9-815-4200; fax: 64-9-815-4202; e-mail. NLallu@hortresearch.co.nz 
At the end of CA storage, and after an additional 4 weeks of air storage at $0{ }^{\circ} \mathrm{C}$, fruit were evaluated for rots and physiological pitting. Linear discriminant analysis (LDA) showed the three $\mathrm{CO}_{2}$ removal systems altered the volatile profiles of the store atmospheres differently. CA storage delayed fruit softening markedly, and once returned to air, softening resumed at a rate equivalent to that of fruit of equivalent firmness that had not been CA stored. There was little effect of $\mathrm{CO}_{2}$ removal system on the fruit softening during storage. Although CA storage resulted in a higher incidence of rots, there was little difference among $\mathrm{CO}_{2}$ removal systems compared to the main effect between air and CA storage. Similarly, CA storage delayed the appearance of physiological pitting, although the incidence increased rapidly during an additional 4 weeks of storage in air, and was higher than for fruit stored throughout in air. Among the $\mathrm{CO}_{2}$ removal systems, $\mathrm{N}_{2}$ flushing resulted in fruit with the lowest incidence of physiological pitting. It is concluded that different $\mathrm{CO}_{2}$ removal systems alter room volatile profiles but may not consistently affect the quality of 'Hayward' kiwifruit during CA storage.

I n commercial CA rooms, $\mathrm{CO}_{2}$ is prevented from accumulating excessively by using either an $\mathrm{AC}$ scrubber, hydrated lime scrubber (or simply placing lime inside the room), or by flushing the rooms with $\mathrm{N}_{2}$. In an AC scrubber, the store atmosphere is passed through a bed of fine mesh activated carbon granules that adsorb the $\mathrm{CO}_{2}$. When the granules are saturated with $\mathrm{CO}_{2}$, they are regenerated by flushing with air, the released $\mathrm{CO}_{2}$ being vented outside the store. The timing and number of cycles of adsorption and regeneration maintain the set $\mathrm{CO}_{2}$ level in the store atmosphere. Lime removes $\mathrm{CO}_{2}$ from the store atmosphere through the reaction of $\mathrm{CO}_{2}$ with calcium hydroxide, and may be included in the CA room, or in a chamber attached to the room through which the store atmosphere is passed intermittently. With the advent of membrane $\mathrm{N}_{2}$ generators, flush- ing rooms with $98.0 \%$ to $99.9 \% \mathrm{~N}_{2}$, either intermittently or continuously, has been used to remove $\mathrm{CO}_{2}$ as well as reduce the $\mathrm{O}_{2}$ concentration. The method chosen for $\mathrm{CO}_{2}$ control to some extent depends on the degree of $\mathrm{CO}_{2}$ control required, and/or whether the atmosphere is to be established in a land-based coolstore, a sea-freight container, or in the hold of a vessel.

Volatiles produced by the fruit, other than $\mathrm{CO}_{2}$, may accumulate in $\mathrm{CA}$ rooms. The volatile profile in a CA room could be affected by the $\mathrm{CO}_{2}$ removal system. With $\mathrm{N}_{2}$ flushing, all volatiles are purged from the room on a pro rata basis, whereas with AC or lime scrubbing, removal of volatiles may be chemically selective as well as being dependent on concentration. Similarly, if catalytic oxidation is used to remove ethylene, as is required for long-term storage of 'Hayward' kiwifruit because of their sensitivity to ethylene, specific volatile compounds may be removed from the store atmosphere.

Aroma volatiles are a significant component of ripe fruit flavor. Fruit ripened during or after CA storage is generally reported to develop lower volatile concentrations than fruit ripened in air immediately after harvest (Thompson, 1998). However, many of these data have been obtained from apples (Malus $\times$ domestica) and having fruit of equivalent ripeness following CA or air storage is not always possible. In addition, the presence or absence of specific compounds in the storage atmosphere may influence the development of disorders in apples (Scott et al., 1995), rots (Archbold et al., 2000), or flavor of the fruit (Hamilton-Kemp et al., 1996). A high incidence of rots in CA-stored 'Hayward' kiwifruit compared to equivalent fruit stored in air has been reported (Manning and Lallu, 1997).

In New Zealand, approximately $10 \%$ (or 5 million trays) of the 'Hayward' kiwifruit crop is stored under CA each season. In addition, the option to ship fresh produce under CA is becoming more available. It is therefore of interest to determine whether $\mathrm{CO}_{2}$ removal systems affect the volatile profiles in CA rooms and the quality of fruit stored in those rooms. In this paper, the effect of three different $\mathrm{CO}_{2}$ removal systems (AC scrubbing, lime scrubbing, and $\mathrm{N}_{2}$ flushing) has been examined on the volatile profiles of CA rooms containing 'Hayward' kiwifruit and on the incidence of physiological and pathological disorders in the fruit.

\section{Methods}

Fruit. 'Hayward' kiwifruit were obtained from orchards in South Auckland, New Zealand, in 1999 and 2000. Different orchards were used in the 1999 and 2000 storage seasons. Fruit that were commercially mature, with firmness $76.5 \mathrm{~N}$ (17.20 lbf) and soluble solids content (SSC) $7.6 \%$ in 1999 , and $72.6 \mathrm{~N}$ (16.32 lbf) and SSC $8.3 \%$ in 2000 , were harvested directly into wooden bins $[\sim 50-\mathrm{kg}(110.2 \mathrm{lb})$ capacity]. The fruit were stored in these wooden bins at $0{ }^{\circ} \mathrm{C}$. At the end of CA storage, fruit were packed by hand into commercial modular bulk packs containing $10 \mathrm{~kg}(22.0 \mathrm{lb})$ of fruit, loose filled, with polybags and held for an additional 4 weeks of storage at $0{ }^{\circ} \mathrm{C}$ in air.

CA storage. Four identical 12$\mathrm{m}^{3}\left(423.8 \mathrm{ft}^{3}\right)$ CA rooms were each loaded with approximately $1500 \mathrm{~kg}$ (3306.9 lb) of 'Hayward' kiwifruit from a single commercial orchard after approximately $3 \mathrm{~d}$ of curing under ambient conditions. Atmospheres of $2 \% \mathrm{O}_{2}$ and $5 \% \mathrm{CO}_{2}$ were established in three of the four stores using $\mathrm{N}_{2}$ flushing, the fourth store being air. Carbon dioxide concentration within the $\mathrm{CA}$ store atmosphere was maintained by AC scrubber, lime scrubber, or $\mathrm{N}_{2}$ flushing. The approximate parameters of operation for each system for 1999 are given in Table 1 . The frequency and duration of the $\mathrm{CO}$ removal cycle was altered slightly for 2000 (slightly more frequent, shorter cycles). Ethylene in the atmosphere from each of the four rooms was scrubbed and maintained at less than $0.03 \mu \mathrm{L} \cdot \mathrm{L}^{-1}$ (ppm) using a platinum/ceramic catalyst scrubber fitted to each room. Atmospheres were broken briefly when fruit were sampled but were re-established as soon as possible thereafter (typically within 6 h), using pure $\mathrm{N}_{2}, \mathrm{CO}_{2}$, and ethylene. The room atmospheres were sampled for volatiles after $6,12,18$, and 27 weeks in 1999 and after 6, 10, and 14 weeks in 2000 . The storage season in 2000 was curtailed after 14 weeks for commercial reasons.

Volatile SAMPLING AND ANALYsIs. Volatile compounds were trapped by drawing the room atmosphere at 50 $\mathrm{cm}^{3}$ (3.1 inch ${ }^{3}$ ) per minute for $20 \mathrm{~min}$ through a stainless steel cartridge filled 
Table 1. Parameters of operation for the activated carbon scrubbing, lime scrubbing, and nitrogen flushing carbon dioxide removal systems used in three controlled atmosphere storage rooms holding 'Hayward' kiwifruit under $2 \%$ oxygen and $5 \%$ carbon dioxide.

\begin{tabular}{lcccc}
\hline System & $\begin{array}{c}\text { Mass of } \\
\text { scrubbing } \\
\text { material }(\mathbf{k g})^{\mathrm{z}}\end{array}$ & $\begin{array}{c}\text { Flow-rate } \\
\left(\mathbf{L} \cdot \mathbf{m i n}^{-1}\right)^{\mathrm{y}}\end{array}$ & $\begin{array}{c}\text { Operation } \\
\text { frequency } \\
(\text { cycles/week) }\end{array}$ & $\begin{array}{c}\text { Operating } \\
\text { cycle } \\
\text { duration (min) }\end{array}$ \\
\hline Activated carbon & 13 & 126 & $2-3$ & $2-5$ \\
Lime & 25 & 30 & $2-3$ & 20 \\
Nitrogen & $\mathrm{na}^{\mathrm{x}}$ & 110 & $2-3$ & 5 \\
\hline
\end{tabular}

${ }^{2} \mathrm{~kg}=2.2 \mathrm{lb}$

$1 \mathrm{~L} \cdot \mathrm{min}^{-1}=61.0 \mathrm{inch}^{3} / \mathrm{min}$

${ }^{\mathrm{x}}$ Not applicable.

with $100 \mathrm{mg}$ Chromosorb 105 (Young and Paterson, 1985). Room volatiles at each timepoint were measured prior to opening the room for fruit sampling, and each room was sampled twice at each timepoint. The volatile-enriched collection cartridges were stored at -15 ${ }^{\circ} \mathrm{C}$ until analyzed (storage was less than 2 weeks). Volatiles were analyzed by gas chromatography (GC) and GC-mass spectrometry (GC-MS). For analysis, the trapped headspace material was thermally desorbed at $175{ }^{\circ} \mathrm{C}$ onto a J\&W DBWax GC column $(30 \mathrm{~m} \times$ $0.32 \mathrm{~mm}$ i.d., 0.5 -um film; Agilent Technologies, Palo Alto, Calif.) using helium as a carrier gas set at a flow rate of $30 \mathrm{~cm}^{3} \cdot \mathrm{s}^{-1}$. The column temperature was programmed as follows: $30{ }^{\circ} \mathrm{C}$, hold $6 \mathrm{~min}, 3^{\circ} \mathrm{C} / \mathrm{min}$ to $102{ }^{\circ} \mathrm{C}, 5$ ${ }^{\circ} \mathrm{C} / \mathrm{min}$ to $190{ }^{\circ} \mathrm{C}$, hold $5 \mathrm{~min}$. The column outlet was split between the GC detector (for quantification) and the MS (for component identification). The flame ionization detector and the MS inlet temperature were set at 220 ${ }^{\circ} \mathrm{C}$. MS ionization was achieved with electron ionization set at $70 \mathrm{eV}$.

Quantification of compounds was carried out using the average detector response based on methyl butanoate, ethyl butanoate, hexanol, and methyl benzoate. Compound identification was by matching mass spectra with those of authentic standards, library spectra (National Institute of Standards and Technology and in-house) and matching of GC retention indices.

Fruit Quality evaluation. Fruit firmness was measured at two positions on the fruit at the midpoint of the long axis at $90^{\circ}$ to each other using an Effegi penetrometer [7.9-mm-diameter (5/16 inch) probe; Facchini, Alfonsine, Italy] after removal of a $1-\mathrm{mm}$ thick $(0.039$ inch $)$ slice of skin and flesh. Firmness was measured prior to fruit warming from storage temperatures on a 20 -fruit sample taken at four fruit per bin or modular bulk pack immediately after the store volatile profiles had been sampled. Fruit flesh color [Commission Internationale de l'Eclairage (CIE) a * value, $D_{65}$ illuminant] was measured for the 1999 samples only on the pared fruit surface prior to penetrometer measurement using a Minolta CR300 Chroma Meter (Minolta Co., Osaka, Japan). The incidence of all rots, excluding those arising from physical damage, was recorded at the end of CA storage and also after the further 4 weeks of air storage. Fungal pitting rots arising from Cryptosporiopsis species were recorded separately from other rot types. Physiological pitting (sunken areas on the fruit surface, often discolored; Manning and Beever, 1992) was scored as present or absent irrespective of severity. Rot and physiological pitting incidence were scored on fruit from 12 modular bulk packs ( $\sim 1000$ fruit) from each of

Data AnAlysis. Volatile concentrations were examined by LDA using S-PLUS 6.1 (Insightful Corp., Seattle, Wash.) for differences among the rooms and for effects of storage time on storage atmospheres. LDA takes all volatiles found and determines which combination gives the best separation of the treatment means. The number of volatiles used for segregation among treatment means differs from one comparison to the next (i.e., each analysis is unique) and are presented with the data. Also, the results presented in the text identify the four principal compounds by which segregation was achieved for each comparison. The relevance of this is examined further in the discussion.

\section{Results}

$\mathrm{CO}_{2}$ Removal systems. LDA showed a significant effect of the $\mathrm{CO}_{2}$ removal system on the room atmosphere volatile profiles in both the four rooms. the 1999 and 2000 seasons (Fig. 1). The three CA rooms were segregated from the air room by the first linear discriminant in 1999 and by the second linear discriminant in 2000. Among the $\mathrm{CA}$ rooms, the $\mathrm{AC}$ room segregated from the lime room with the $\mathrm{N}_{2}$ flushed room being intermediate by the second linear discriminant in 1999 and all CA rooms segregated by the first linear discriminant in 2000. The principal compounds by which room segregation was achieved in 1999 were propanal, hexanal, butanal, and acetic acid for first linear discriminant, and acetic acid, ethyl acetate, butanoic acid, and propanoic acid for the second linear discriminant. In 2000, segregation was by butanoic acid, nonanal, hexanoic acid, and pentanoic acid for first linear discriminant and butanoic acid, pentanoic acid, propanoic acid, and decanal for second linear discriminant. It is noticeable that the main compounds for discrimination between air and CA rooms were aldehydes in 1999 and organic acids in 2000, whereas the discrimination among $\mathrm{CA}$ rooms was mainly by organic acids in both years.

STORAGE PERIOD. The LDA analysis in 1999 segregated the room atmospheres by storage period by both first and second linear discriminants (Fig. 2). Segregation of the 6-week samples from the 12- and 18-week samples was mainly by the second linear discriminant whereas segregation of the 27-week sample from the 12 - and 18 -week samples was mainly by the first linear discriminant. The main compounds by which LDA segregated the effect of storage period were E2-hexenal, hexanal, ethyl acetate and methyl acetate for the first linear discriminant, and hexanal, E-2-hexenal, hexanol, and methyl acetate for the second linear discriminant.

The main classes of volatile compounds accumulating in the room atmospheres in 1999 were alcohols, with lower concentrations of aldehydes and organic acids (Fig. 3). Alcohols were higher in the atmospheres of the CA rooms than in the air room, and tended to increase with storage with little consistent difference among $\mathrm{CO}$ removal systems. Aldehydes in the $\mathrm{AC}^{2}$ room were consistently the highest and generally levels were higher in the CA atmospheres than in air after 12 and 18 weeks of storage. There was little consistent trend in organic acids in the rooms through storage. 


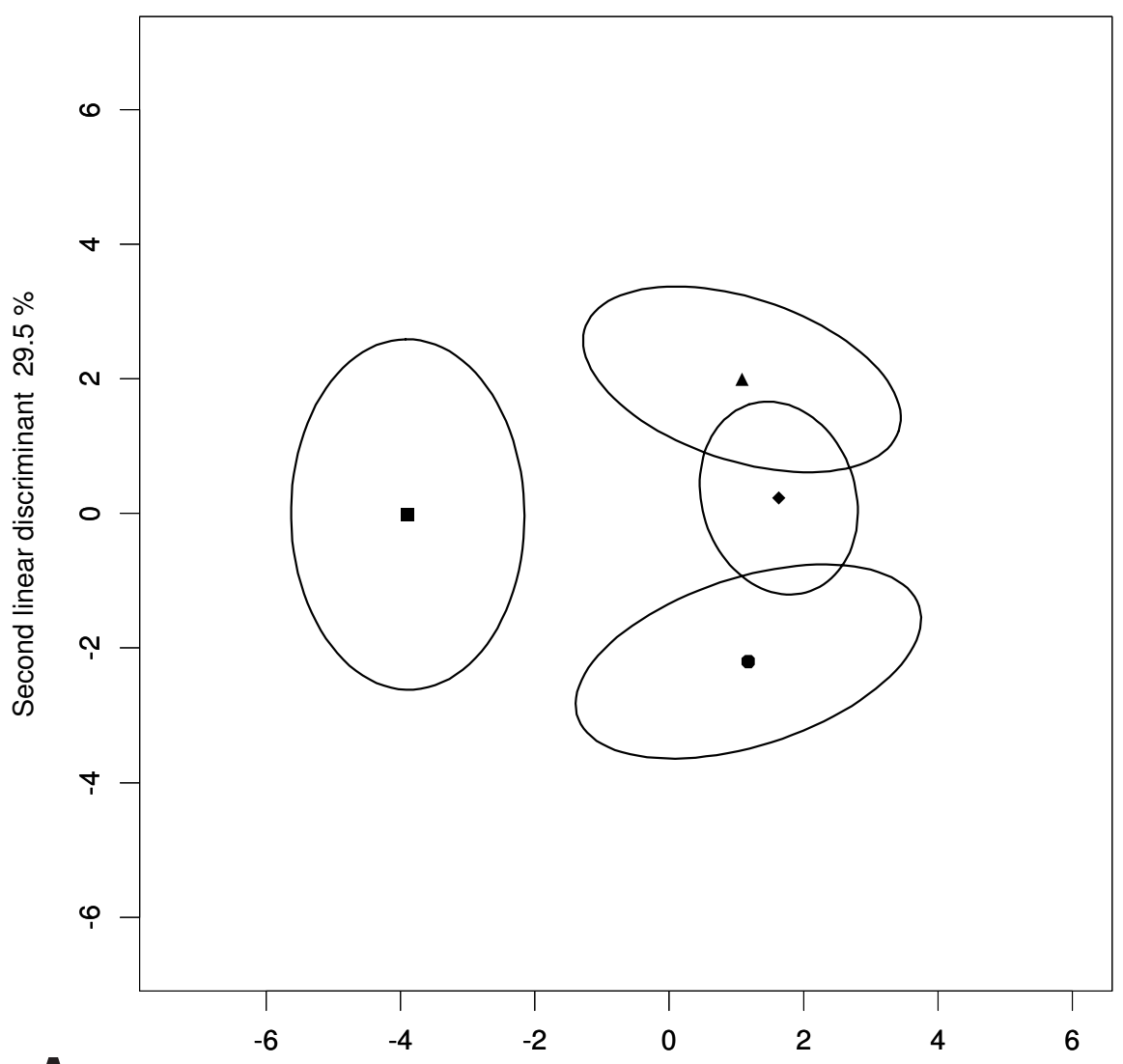

A

First linear discriminant $67.9 \%$

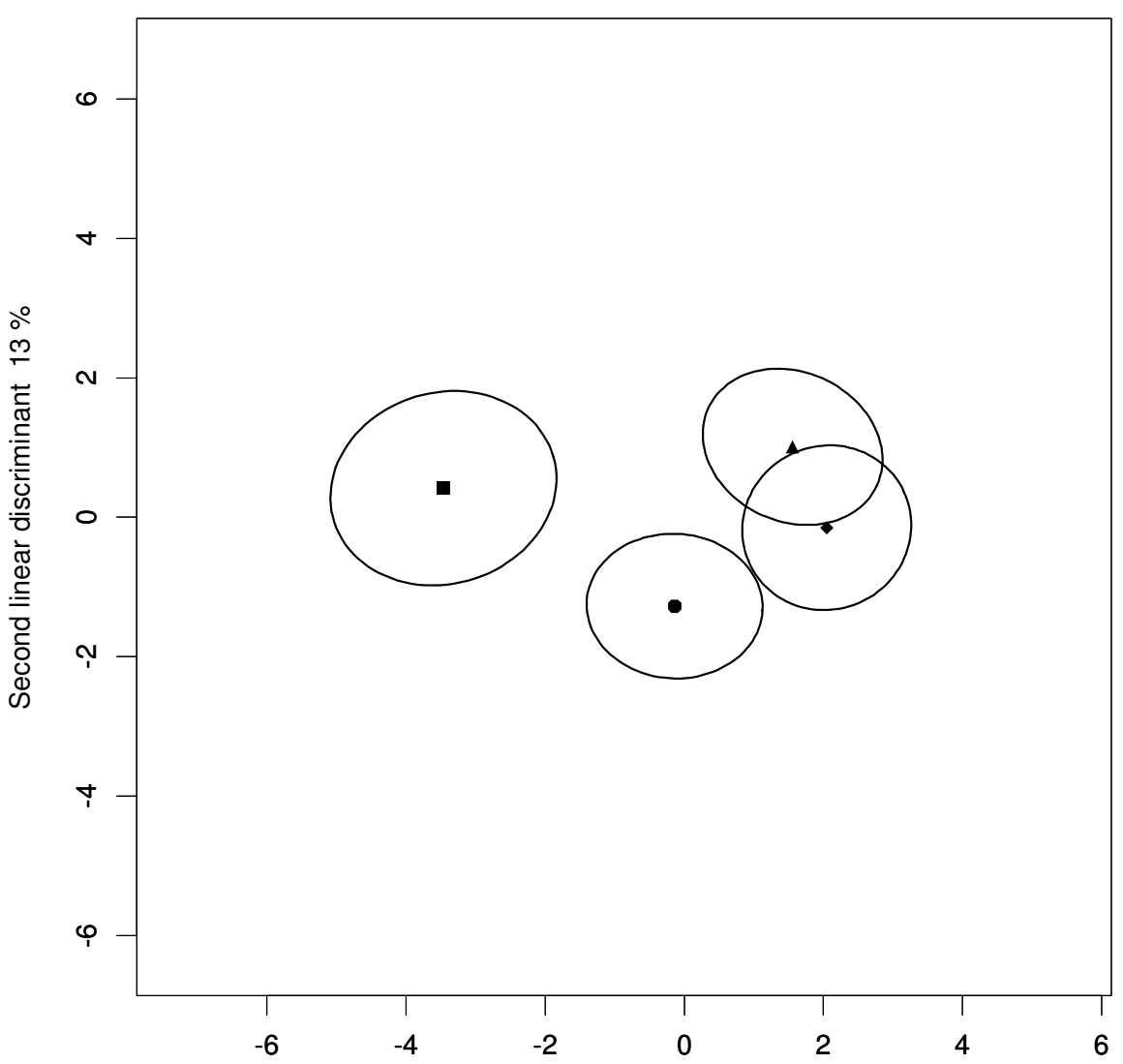

B

First linear discriminant $84.9 \%$
The LDA analysis in 2000 segregated the room atmospheres by storage period by both first and second linear discriminants (Fig. 2). The main compounds by which LDA segregated the effect of storage period were butanoic acid, propanoic acid, formic acid, and acetic acid for first linear discriminant and butanoic acid, acetic acid, nonanal, and propanoic acid for second linear discriminant. This concurs with organic acids being factors in discrimination among the $\mathrm{CO}_{2}$ removal systems.

During storage in 2000, the main classes of volatile compounds (alcohols, aldehydes and organic acids) decreased with increased storage period (Fig. 3). The predominant classes of volatiles were the aldehydes and organic acids contrasting with the dominance of alcohols in 1999 (Fig. 3).

Fruit FIRMNESS. All CA-stored fruit were firmer than air-stored fruit throughout the storage period in 1999 (Fig. 4). There was a range of approximately $9 \mathrm{~N}$ (2.0 lbf) of firmness among fruit held in the three $\mathrm{CO}_{2}$ control systems after 27 weeks of $\mathrm{CA}^{2}$ storage, with fruit held under AC scrubbing being approximately $9 \mathrm{~N}$ softer than fruit under $\mathrm{N}_{2}$ flushing, although this difference was not consistent throughout storage. Fruit softening progressed more rapidly after transfer from CA to air storage than had occurred during CA storage. However, the rate of softening after transfer to air from CA was approximately similar to that of fruit of equivalent firmness that had been held continuously in air storage.

In 2000 , there was no effect of $\mathrm{CO}_{2}$ removal systems on the firmness of fruit after 14 weeks of CA storage with all the fruit in the approximate range 60-65 N (13.5-14.6 lbf), although the CA-stored fruit were all firmer than the air-stored fruit by approximately

Fig. 1. Linear discriminant analysis (LDA) map segregating the effect of controlled atmosphere ( $2 \%$ oxygen and $5 \%$ carbon dioxide) storage using activated carbon scrubbing $(\mathbf{O})$, lime scrubbing (A), or nitrogen flushing $(\diamond)$ for carbon dioxide removal, or air storage ( $\square$ ), on the volatile profile of atmospheres from storage rooms holding 'Hayward' kiwifruit at $0{ }^{\circ} \mathrm{C}$ $\left(32.0^{\circ} \mathrm{F}\right)$ in $1999(\mathrm{~A}$, top $)$ or 2000 (B, bottom). Data for different storage periods have been combined. LDA based on 11 compounds in 1999 and eight compounds in 2000, mean and 95\% confidence interval shown. 

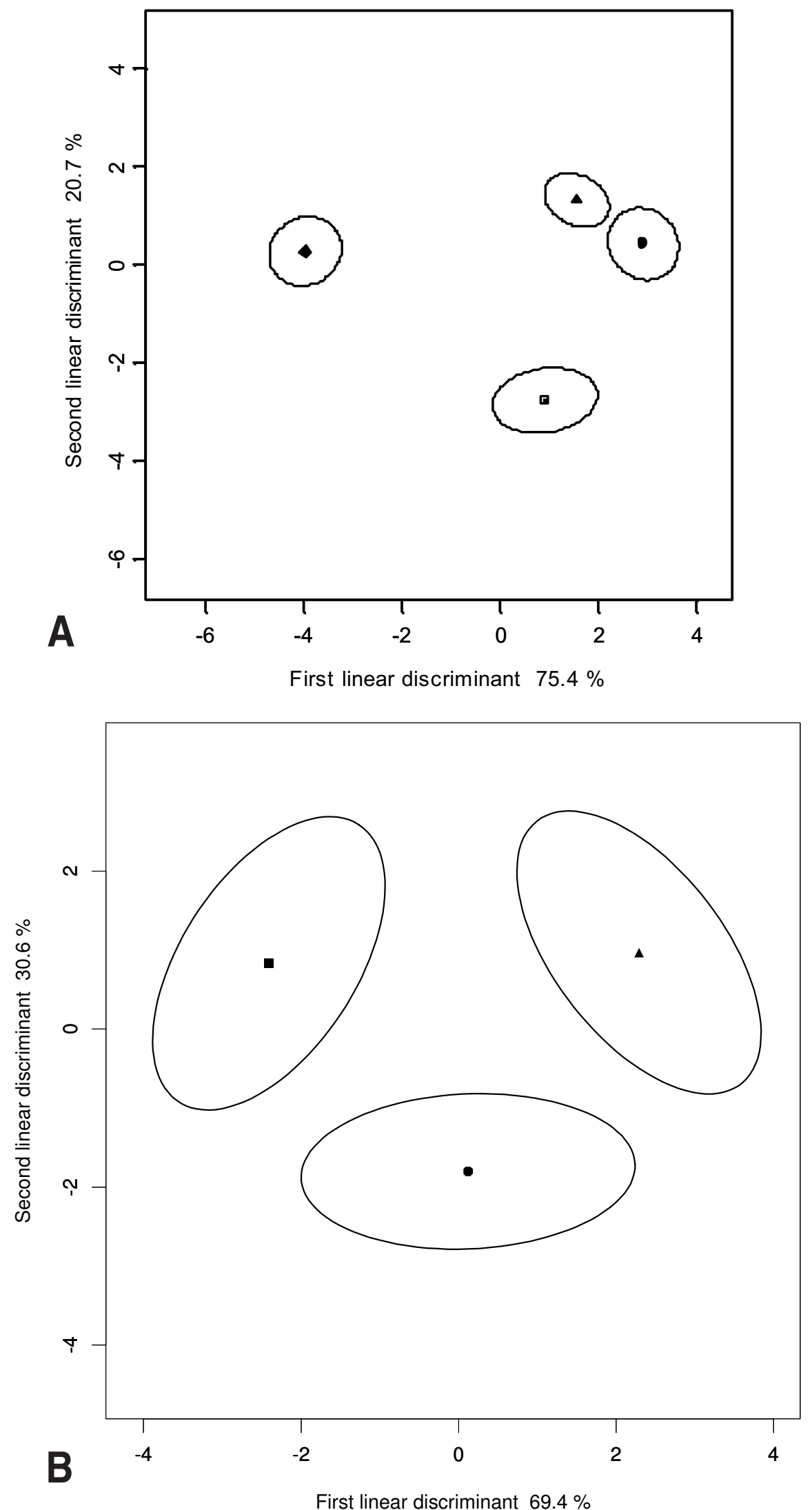

$30 \mathrm{~N}$ (6.7 lbf). No further firmness data from 2000 is presented.

Rots. After 27 weeks of storage in 1999, the incidence of rots in CAstored fruit was between seven and nine times higher than for fruit stored in air (Fig. 5). The incidence of rots increased during the 4 weeks of air storage after the end of CA, irrespective of $\mathrm{CO}_{2}$ removal system. The majority of rots were assessed to be ripe rots caused by latent infections of Cryptosporiopsis species, despite fruit not being close to ripe (soft). Fruit firmness was approximately $49-59 \mathrm{~N}$ (11.0-13.3 lbf) at the end of CA storage, and 29-39 $\mathrm{N}$ (6.5-8.8 lbf) after the subsequent 4 weeks of storage in air.

In 2000 , the incidence of rots after storage was low $(<2.5 \%)$, compared to that in 1999, although the incidence in fruit stored under CA was approximately twice that of fruit in air storage $(2 \%$ to $2.5 \%$ compared to $1 \%$, respectively). There was no obvious effect of $\mathrm{CO}_{2}$ removal system on the incidence of rots. No further rot data from 2000 is presented.

Physiological pitTing. After 27 weeks of storage in 1999 the incidence of physiological pitting was lower in CA-stored fruit than in air-stored fruit (Fig. 6), with the incidence in fruit held in the $\mathrm{N}_{2}$ flushed room being lower than in fruit in the $\mathrm{AC}$ or lime-scrubbed rooms. However, during a 4 -week period of air storage following the CA storage, the incidence of physiological pitting increased markedly in the previously CA-stored fruit, while there was little change in the continuously air-stored fruit. The final incidence of physiological pitting in fruit stored with lime scrubbing was approximately twice that in the $\mathrm{N}_{2}$ flush-stored fruit with the AC-scrubbed fruit intermediate. This suggests that there may be an effect of $\mathrm{CO}_{2}$ removal system on the development of physiological pitting after CA storage.

The incidence of physiological pitting in 2000 was too low for comparison, being $<0.3 \%$ in all treatments. This may reflect the short storage period as much as any lack of seasonal or orchard disposition in the fruit to disorder.

Fig. 2. Linear discriminant analysis (LDA) map segregating the effect of storage period on the volatile profile of atmospheres in storage rooms holding 'Hayward' kiwifruit at $0^{\circ} \mathrm{C}\left(32.0^{\circ} \mathrm{F}\right)$ in 1999 (A, top: 6 weeks $\square, 12$ weeks $\bullet$, 18 weeks $\Delta, 27$ weeks $\diamond)$ and 2000 (B, bottom: 6 weeks $\square, 10$ weeks $\bullet, 14$ weeks $\Delta)$. Data for air and controlled atmosphere $(2 \%$ oxygen and $5 \%$ carbon dioxide) rooms have been combined. LDA based on 15 compounds in 1999 and eight compounds in 2000 , mean and $95 \%$ confidence interval shown. 
Fig. 3. Alcohol, aldehyde, and organic acid content of storage room atmospheres during $0{ }^{\circ} \mathrm{C}\left(32.0^{\circ} \mathrm{F}\right)$ storage of 'Hayward' kiwifruit in controlled atmosphere ( $2 \%$ oxygen and $5 \%$ carbon dioxide) using activated carbon scrubbing (O), lime scrubbing $(\Delta)$ or nitrogen flushing $(\diamond)$ for carbon dioxide removal, or air storage (ם) in 1999 and 2000. Values are the average of two samples per store at each timepoint.
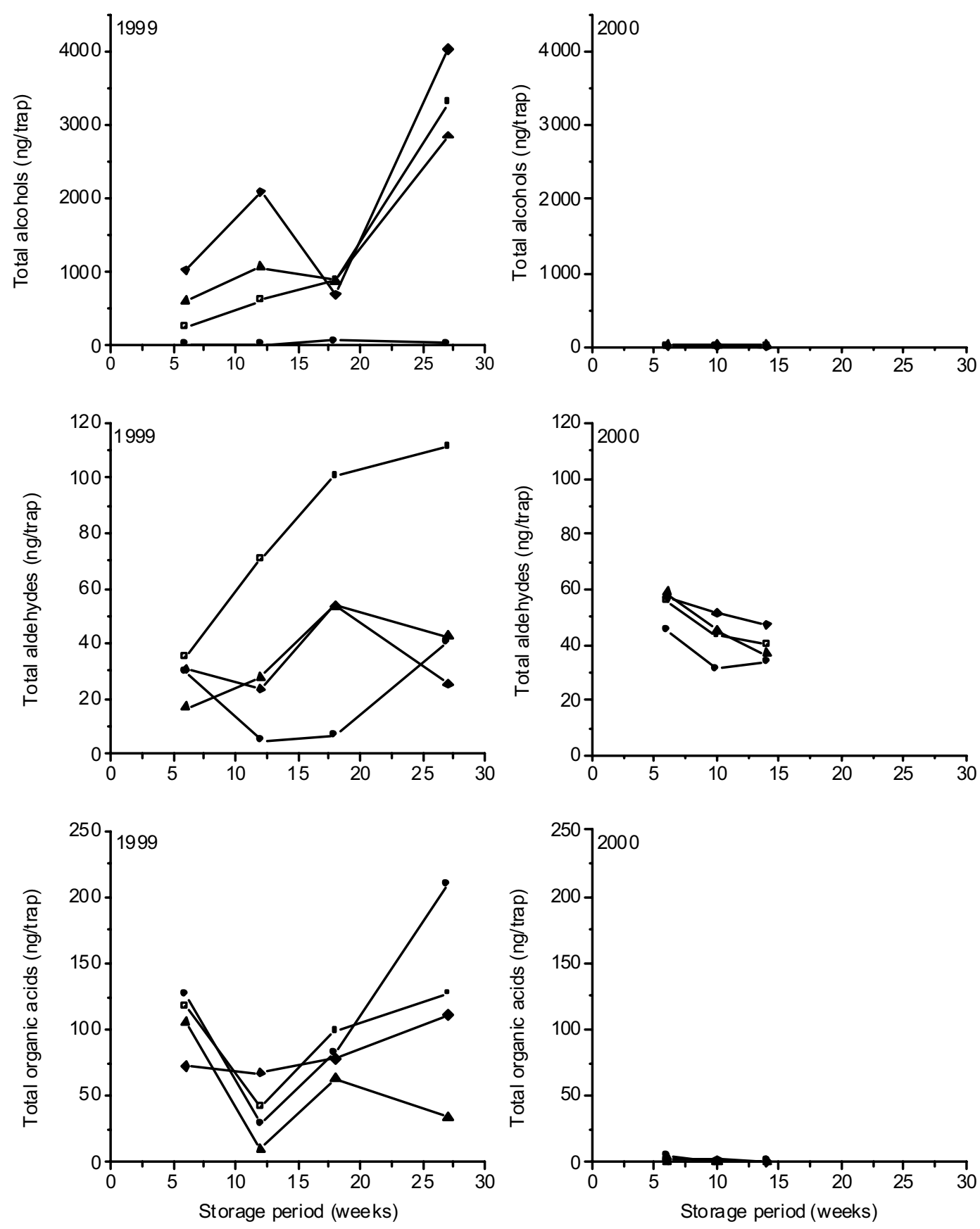

Fruit Flesh COLOR. After 27 weeks of storage in 1999, the fruit flesh color of CA-stored fruit was visibly more green $\left(a^{*}\right.$ more negative value) than for air-stored fruit: air-stored fruit $\mathrm{a}^{*}=-8.7$; CA-stored fruit $\mathrm{a}^{*}$ in the range -11.1 to -12.0 . There was a slight effect of $\mathrm{CO}_{2}$ removal system, with fruit held under AC scrubbing being slightly less green $\left(a^{*}=-11.1\right)$ than fruit held in the lime-scrubbed or $\mathrm{N}_{2}$-flushed rooms (both $\mathrm{a}^{*}=-12.0$ ). In 2000, differences between treatments were not visible and no chroma meter readings were taken.
Fig. 4. Firmness of 'Hayward' kiwifruit stored in controlled atmosphere [CA ( $2 \%$ oxygen and $5 \%$ carbon dioxide)] using activated carbon scrubbing $(\bullet)$, lime scrubbing $(\Delta)$ or nitrogen flushing (४) for carbon dioxide removal, or air storage (घ) at $0^{\circ} \mathrm{C}\left(32.0^{\circ} \mathrm{F}\right)$ in 1999. CA stored fruit were transferred to air storage after 27 weeks of CA. Error bars $= \pm S E ; 20$ fruit per sample; $1 \mathrm{~N}=$ $0.225 \mathrm{lbf}$.

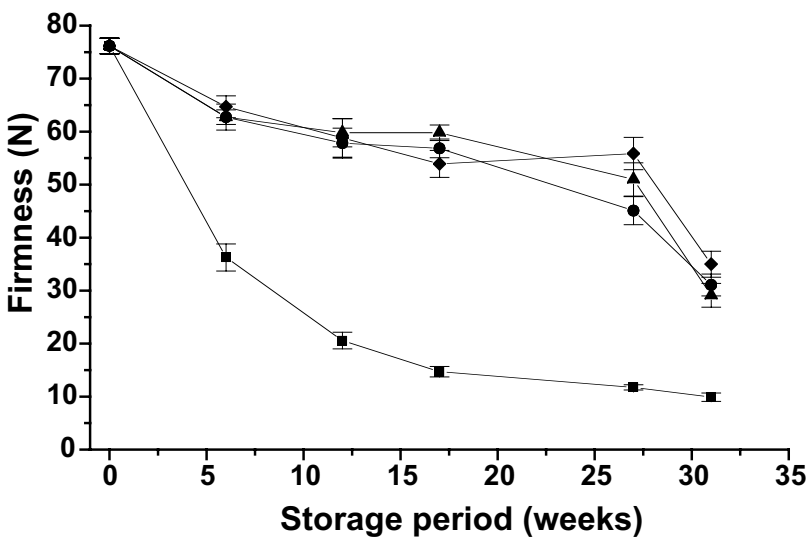

Hortlechnology • April-June 2005 15(2) 

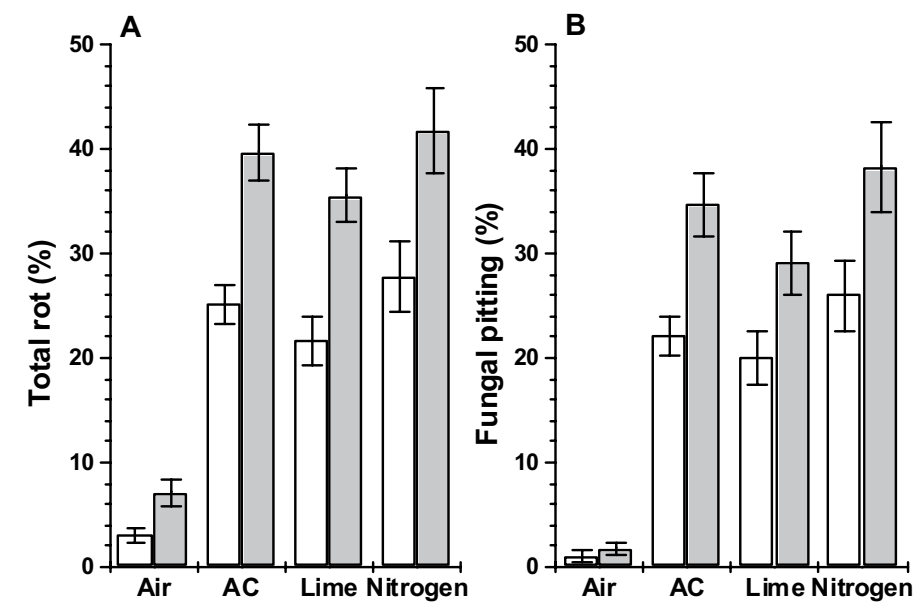

Fig. 5. Incidence of total rots (A) or fungal pitting (B) in 'Hayward' kiwifruit after storage in controlled atmosphere [CA ( $2 \%$ oxygen and $5 \%$ carbon dioxide)] using activated carbon scrubbing (AC), lime scrubbing or nitrogen flushing for carbon dioxide removal, or air at $0{ }^{\circ} \mathrm{C}\left(32.0{ }^{\circ} \mathrm{F}\right)$ in 1999 . Data is shown for the rot incidence after 27 weeks (open bars) or after 27 weeks under air or CA storage plus 4 weeks of air storage (shaded bars). Values are for 12 modular bulk packs of fruit (approximately 1000 fruit in total) assessed from each storage room. Error bars $= \pm$ SE.

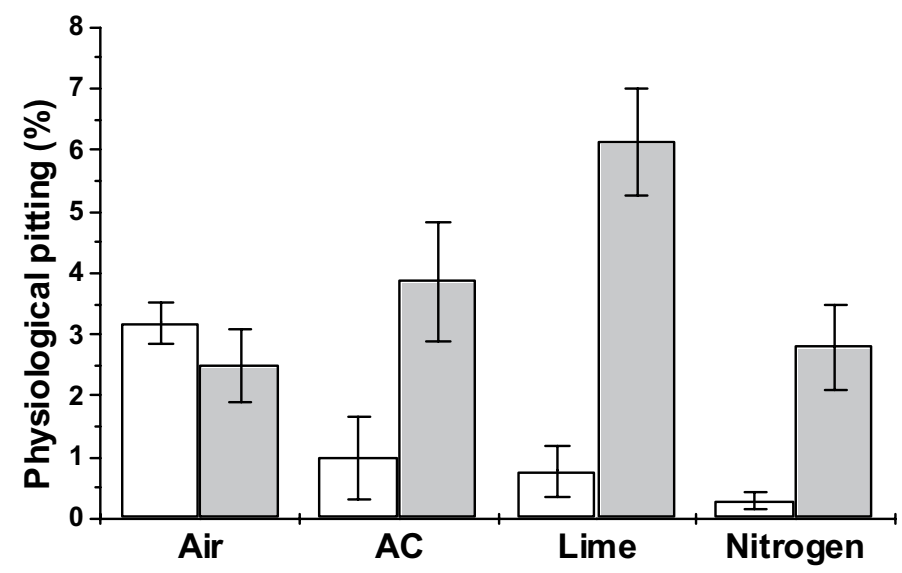

Fig. 6. Incidence of physiological pitting in 'Hayward' kiwifruit after storage in controlled atmosphere [CA $(2 \%$ oxygen and $5 \%$ carbon dioxide $)]$ using activated carbon scrubbing (AC), lime scrubbing or nitrogen flushing for carbon dioxide removal, or air at $0{ }^{\circ} \mathrm{C}\left(32.0{ }^{\circ} \mathrm{F}\right)$ in 1999 . Data is shown for the physiological pitting incidence after 27 weeks (open bars) or after 27 weeks under air or CA storage plus 4 weeks of air storage (shaded bars). Values are for 12 modular bulk packs of fruit (approximately 1000 fruit in total) assessed from each storage room. Error bars $= \pm$ SE.

\section{Discussion}

Within the industry, the use of different $\mathrm{CO}_{2}$ removal systems depends on the phase of storage and/or seasonal factors. For example, $\mathrm{N}_{2}$ flushing may be used for initial $\mathrm{O}_{2}$ reduction in a $\mathrm{CA}$ store that would normally have its $\mathrm{CO}_{2}$ scrubbed with an AC scrubber, but in a season when fruit have high respiratory activity normal AC scrubbing may have to be supplemented by the use of hydrated lime, although no stores in New Zealand rely solely on lime or $\mathrm{N}_{2}$ flushing for $\mathrm{CO}_{2}$ control. Irrespec- tive of which $\mathrm{CO}_{2}$ removal system is utilized, the systems examined appear unlikely to have a major effect on fruit quality, although the store atmospheres may have significantly different volatile compositions.

Linear discriminant analysis of the volatile compounds accumulating in the stores during storage was capable of discriminating among rooms on the basis of the $\mathrm{CO}_{2}$ removal system in both seasons. The fact that segregation among rooms was achieved despite there being markedly different volatile compositions between the seasons is perhaps surprising, or coincidental. However, it does suggest that the choice of $\mathrm{CO}_{2}$ removal system may alter the volatiles that stored fruit are exposed to during CA storage.

The difference between the store volatile compositions for the seasons appears to be the result of the response of the fruit to the low $\mathrm{O}_{2}$ and/or high $\mathrm{CO}_{2}$ applied during CA storage. While the $\mathrm{O}_{2}$ concentration during storage was maintained at $2 \%$ and the $\mathrm{CO}_{2}$ concentration at $5 \%$ for both seasons, the response of the fruit differed, with a greater production of ethanol in 1999 compared to in 2000 (Burdon et al., 2005 ). This suggests the possibility of a different susceptibility of the fruit to low $\mathrm{O}_{2}$ between the two seasons, possibly a result of orchard or seasonal environmental conditions prior to harvest. It is known commercially that performance of fruit in CA may differ among orchards or from year to year. While additional shut-off valves were fitted to the AC scrubbers between the seasons in order to more completely prevent any passive diffusion of $\mathrm{CO}_{2}$ or volatiles into the scrubber, the basis for differences in the store atmospheres appeared to be the fruit, with the fruit in 1999 producing higher concentrations of alcohols, principally ethanol, than in 2000. The lack of compounds identified as important volatiles to 'Hayward' kiwifruit flavor (e.g., ethyl butanoate, Gilbert et al., 1995) in the store atmospheres is expected, as kiwifruit, unlike apples, only start to produce fruity ester volatiles (such as ethyl butanoate) once the fruit are at or near eating ripeness or are very soft (Young and Paterson, 1985). Also, the production of some of these compounds is likely to be dependent on tissue disruption and production of volatiles from lipoxygenase activity, and therefore, likely to be produced only in very low concentrations by intact fruit (Riley and Thompson, 1998).

While the $\mathrm{CO}_{2}$ removal system did not influence the rate of fruit softening among CA rooms, all CA fruit retained firmness well during CA storage and then on transfer to air softened at a rate equivalent to fruit of a similar firmness that had only been held in air storage. Within the industry, it is often claimed that fruit soften more rapidly after CA storage. However, this softening appears to be a matter of comparing relative rates. While the softening rate 
was certainly faster after CA than when in CA, it was actually the same as for fruit of an equivalent firmness that had been stored in air.

An aspect of 'Hayward' kiwifruit that is important to the consumer appeal of the fruit is a "fresh" green color to the flesh. The CA-stored fruit in 1999 had visibly greener flesh than the air-stored fruit, providing another benefit of CA storage, in addition to firmness retention. The fruit stored under the $\mathrm{N}_{2}$ flush and lime scrubbing systems had marginally better color retention than fruit stored under the AC scrubbing system.

Despite the positive effects of CA on fruit firmness and flesh color, there were some negative effects related to the development of rots and physiological pitting. In both seasons the incidence of rots in CA stored fruit was higher than for fruit stored in air, but there was no effect of $\mathrm{CO}_{2}$ removal system on the incidence of rots. While the majority of the rots were what would be termed ripe rots, the fruit both immediately out of CA, and after a subsequent 4 weeks of air storage, were still firm and not ripe. This suggests that the CA conditions (either low $\mathrm{O}_{2}$, high $\mathrm{CO}_{2}$ or volatile compounds) had either made the fruit susceptible to rots earlier in ripening than would normally happen, or that it had stimulated the fungal growth on unripe fruit (Manning and Lallu, 1997). Recently, high $\mathrm{CO}_{2}$ or a rapid establishment of $\mathrm{CO}_{2}$ in the storage atmosphere has been shown in some instances to increase the incidence of rots and physiological pitting in 'Hayward' kiwifruit during air storage subsequent to CA storage (Lallu et al., 2003).

The effect of CA and $\mathrm{CO}_{2}$ removal methods on aspects of fruit quality, including rot and disorder incidence, may be related to the presence or absence of specific volatiles in the storage atmosphere. Recent work on rots has demonstrated the growth inhibiting or promoting effects of specific volatile compounds, including the common 'Hayward' kiwifruit volatiles hexanal and E-2-hexenal (Archbold et al., 2000; Song et al., 1996; Yuen et al., 1995). The results presented suggest that while CA increased the incidence of rots in stored kiwifruit, the volatile composition that occurred under different $\mathrm{CO}_{2}$ removal systems did not have a major effect. However, the very high incidence of rots in the 1999 season and the low incidence from the curtailed storage period in 2000 may have negated any more subtle effect of volatiles. Alternatively, the higher occurrence of ethanol in fruit in the 1999 season may be related to rot incidence.

CA storage reduced the incidence of physiological pitting visible immediately on removal of the fruit from storage, although the incidence in the CA stored fruit increased dramatically during the subsequent 4 weeks of air storage. This post-CA increase in physiological pitting was least in the fruit stored with $\mathrm{N}_{2}$ flushing compared to the lime-or AC-scrubbed samples, possibly suggesting that flushing the room was beneficial compared to the other two closed systems because volatiles are involved in the induction or expression of physiological pitting. However, although the highest incidence of physiological pitting occurred in the season where the ethanol content of the rooms increased during storage and was higher in 1999 than 2000 , this is likely to be coincidental since fruit held in air also developed physiological pitting, but the ethanol was virtually nil in this room. Rather than volatiles inducing physiological pitting it may be that a consequence of the development of physiological pitting is the production of specific volatiles or an altered volatile profile by predisposed fruit.

The propensity to develop physiological pitting and fungal pitting may be linked since in the 1999 season the highest incidence of physiological pitting amongst $\mathrm{CO}_{2}$ removal systems was in the lime system which had the lowest incidence of fungal pitting. Fruit may develop either fungal pitting or physiological pitting depending on the interaction of preharvest factors and the storage environment. The apparent decrease in the incidence of physiological pitting in air-stored fruit between weeks 27 and 31 is likely to be due to rots invading the tissue damaged by physiological pitting.

In conclusion, the use of different $\mathrm{CO}_{2}$ removal systems to control elevated $\mathrm{CO}_{2}$ levels during CA storage of 'Hayward' kiwifruit affected the volatile profiles in the CA rooms. However, there was little difference among $\mathrm{CO}_{2}$ removal systems on aspects of fruit quality measured either during, or at the end of the storage period, particularly when compared to the large effects of CA compared to air storage on fruit firmness, rots and physiological pitting. $\mathrm{N}_{2}$ flushing may reduce the incidence of physiological pitting compared to other $\mathrm{CO}_{2}$ removal systems. The lack of any major effect on fruit quality shows all three $\mathrm{CO}_{2}$ removal systems to be suitable for controlling $\mathrm{CO}_{2}$ during $\mathrm{CA}$ storage of 'Hayward' kiwifruit.

\section{Literature cited}

Archbold, D.D., T.R. Hamilton-Kemp, and E. Fallik. 2000. Aroma volatiles as modulators of postharvest mold development on fruit: In vivo role and fumigation tools. Acta Hort. 518:87-92.

Burdon, J., N. Lallu, D. Billing, D. Burmeister, C. Yearsley, M. Wang, A. Gunson, and H. Young. 2005. Carbon dioxide scrubbing systems alter the ripe fruit volatile profiles in controlled atmosphere stored 'Hayward' kiwifruit. Postharvest Biol.Technol. 35:133-141.

Gilbert, J.M., H. Young, and S.H. Murray. 1995. Volatile flavor compounds affecting consumer acceptability of kiwifruit. J. Sensory Studies 11:247-259

Hamilton-Kemp, T.R., D.D. Archbold, J.H. Loughrin, R.W. Collins, and M.E. Byers. 1996. Metabolism of natural volatile compounds in strawberry fruit. J. Agr. Food Chem. 44:2802-2805.

Lallu, N., J. Burdon, C. Yearsley, and D. Billing. 2003. Commercial practices for controlled atmosphere storage of 'Hayward' kiwifruit. Acta Hort. 610:245-251.

Manning, M. and D. Beever. 1992. An update on storage pitting research. N.Z. Kiwifruit. February:5-7.

Manning, M.A. and N. Lallu. 1997. Fungal diseases of kiwifruit stored in controlled atmosphere conditions in New Zealand. Acta Hort. 444(2):725-731

Riley, J.C.M. and J.E. Thompson. 1998. Ripening-induced acceleration of volatile aldehyde generation following tissue disruption in tomato fruit. Physiol. Plant. 104(4):571-576.

Scott, K.J., C.M.C. Yuen, and F. Ghahramani. 1995. Ethanol vapour-A new anti-scald treatment for apples. Postharvest Biol. Technol. 6(3-4):201-208

Song, J., R. Leepipattanawit, W. Deng, and R.M. Beaudry. 1996. Hexanal vapor is a natural, metabolizable fungicide: Inhibition of fungal activity and enhancement of aroma biosynthesis in apple slices. J. Amer. Soc. Hort. Sci. 121(5):937-942.

Thompson, A.K. 1998. Controlled atmosphere storage of fruits and vegetables. CAB Intl., Wallingford, U.K.

Young, H. and V.J. Paterson. 1985. The effects of harvest maturity, ripeness and storage on kiwifruit aroma. J. Sci. Food Agr. 36:352-358.

Yuen, C.M.C., J.E. Paton, R. Hanawati, and L.Q. Shen. 1995. Effects of ethanol, acetaldehyde and ethyl formate vapour on the growth of Penicillium italicum and P. digitatum on oranges. J. Hort. Sci. 70(1):81-84. 